\title{
Assessment of Pulse Wave Velocity as Arterial Stiffness Parameter in Adolescent Elite Wrestlers
}

\section{Adolesan Elit Güreşçilerde Arteriyel Sertlik Parametresi Olarak Nabız Dalga Hizının Değerlendirilmesi}

\author{
Ejder Berk ${ }^{1}$, Adnan Demirel ${ }^{2}$ \\ ${ }^{1}$ Department of Physical Medicine and Rehabilitation, Faculty of Medicine, Sütçü Imam University, \\ Kahramanmaraş, Turkey \\ ${ }^{2}$ Department of Physical Medicine and Rehabilitation, State Hospital, Bingöl, Turkey
}

E. Berk (iD)

0000-0002-0816-0960

\section{A. Demirel \\ 0000-0002-2974-8560}

Geliş Tarihi / Date Received: 12.03.2018

Kabul Tarihi / Date Accepted: 06.05.2018

Yayin Tarihi/Published Online: 03.08.2018

Yazışma Adresi /

Corresponding Author:

Ejder Berk

Sütçü İmam Üniversitesi Tıp

Fakültesi Fiziksel Tip ve

Rehabilitasyon AD,

Kahramanmaraş, Turkey

E-mail:ejder.berk@hotmail.com

C2018 Türkiye Spor Hekimleri Derneği. Tüm hakları saklıdır.

\section{ABSTRACT}

Objective: To compare the arterial stiffness parameter in adolescent elite wrestlers who perform regular heavy exercise with the sedentary control group in the same age range.

Materials and Methods: A group of 23 male wrestlers and a control group of 23 nonathlete males of the same age were compared. The age, height, body weight, resting pulse and blood pressure measurements of the subjects were performed. Pulse wave velocity (PWV) was measured using a photoplethysmography device.

Results: There was no significant difference for age in the athlete $(16.0 \pm 1.1 \mathrm{yrs})$ and control groups $(15.9 \pm 0.9 \mathrm{yrs})$ ( $p>0.05)$. Body mass index (BMI) levels of the control group $\left(19.5 \pm 2.4 \mathrm{~kg} / \mathrm{m}^{2}\right)$ were significantly lower than those of the athlete group $(23.6 \pm$ $\left.3.8 \mathrm{~kg} / \mathrm{m}^{2}\right)(\mathrm{p}<0.001)$. Resting heart rate and arterial blood pressure levels $(67.0 \pm 8.0$ beats/min and $100 \pm 6 / 70 \pm 5 \mathrm{mmHg}$, respectively) of the athletes was significantly lower $(p<0.001)$ than those of the control group $(78 \pm 7$ beats $/ \mathrm{min}$ and $111 \pm 8 / 81 \pm 3 \mathrm{mmHg}$, respectively). The PWV scores of the control group $(4.66 \pm 0.16 \mathrm{~m} / \mathrm{s})$ were significantly higher than those of the athlete group $(4.41 \pm 0.18 \mathrm{~m} / \mathrm{s}),(p<0.001)$.

Conclusion: Arterial stiffness is an independent assessment of cardiovascular disease and mortality for athletes. This study, which aims to evaluate the effects of exercise on arterial stiffness with PWV measurement in adolescent wrestlers, is believed to help determining how arterial function responds to intense exercise practice.

Keywords: Wrestling, arterial stiffness, pulse wave velocity

öz

Amaç: Düzenli ağır egzersiz yapan adolesan elit güreşçilerde arteriyel sertlik parametresinin, aynı yaş aralığındaki sedanter kontrol grubuyla karşılaştırılmasıdır.

Gereç ve Yöntemler: Adolesan erkek güreşçilerden oluşan 23 kişilik atlet grubuyla aynı yaşlardaki sporcu olmayan 23 kişilik erkek kontrol grubu karşılaştırıldı. Atlet ve kontrol grubunun yaş, boy, vücut ağırlığı, istirahat nabzı ve kan basıncı ölçümleri yapıldı. Fotopletismografi cihazı kullanılarak nabız dalga hızları (NDH) ölçüldü.

Bulgular: Atlet grubu $(16.0 \pm 1.05$ yıl) ile kontrol grubu $(15.9 \pm 0.9$ yıl $)$ arasında yaş açısından anlamlı farklılık yoktu ( $p>0.05$ ). Kontrol grubunun vücut kütle indeksi (VKi) değerleri $\left(19.5 \pm 2.4 \mathrm{~kg} / \mathrm{m}^{2}\right)$ atlet grubundan $\left(23.6 \pm 3.8 \mathrm{~kg} / \mathrm{m}^{2}\right)$ anlamlı düzeyde düşüktü. 
$(\mathrm{p}<0.001)$. Atlet grubunun istirahat nabız ölçüm değerleri $(67.0 \pm 8.0$ atım/dk) ve arteriyel tansiyon $(100 \pm 6 / 70 \pm 5$ $\mathrm{mmHg}$ ) değerleri, kontrol grubu değerlerinden (sırasıyla $78.0 \pm 7.0$ atım/dk ve $(111 \pm 8 / 81 \pm 3 \mathrm{mmHg}$ ) arteriyel tansiyon anlamlı olarak düşüktü $(\mathrm{p}<0.001)$. Kontrol grubunun $\mathrm{NDH}$ değerleri $(4.66 \pm 0.16 \mathrm{~m} / \mathrm{s})$ atlet grubununkinden $(4.41 \pm 0.18 \mathrm{~m} / \mathrm{s})$ anlamlı olarak yüksekti $(\mathrm{p}<0.001)$.

Sonuç: Arteriyel sertlik sporcular için kardiyovasküler hastalık ve mortalitenin bağımsız bir değerlendirme ölçütüdür. Adolesan güreşçilerde egzersizin arteriyel sertlik üzerindeki etkilerini NDH ölçümü ile değerlendirmeyi amaçlayan bu çalışmanın, arter fonksiyonlarının yoğun egzersiz uygulamalarına nasıl yanıt verdiğini belirlemeye yardımcı olacağına inaniyoruz.

Anahtar Sözcükler: Güreş, arteriyel sertlik, nabız dalga hızı

Available at: http://journalofsportsmedicine.org and http://dx.doi.org/10.5152/tjsm.2018.106

Cite this article as: Berk E, Demirel A. Assessment of pulse wave velocity as arterial stiffness parameter in adolescent elite wrestlers. Turk J Sports Med. 2018;53(4):167-73.

\section{GİRIŞ}

Güreş; patlayıcı güç, dinamik ve izometrik kuvvet kullanmayı gerektiren; dayanıklılık, çabukluk ve esnekliğe dayalı aerobik ve anaerobik egzersiz performansının kombine sergilendiği antik bir spordur. Dünyada en eski dövüş sporlarından olup, ülkemizde de önde gelen geleneksel spor dalları arasindadır (1).

Cinsiyet ve güreş stilinden bağımsız olarak maç süresindeki eforu devam ettirmek ve dinlenme dönemindeki motivasyonu sağlamak için optimal düzeyde kardiyorespiratuvar fiziksel uygunluk düzeyine ihtiyaç vardır ve bu nedenle güreşçiler uzun süreli ve ağır egzersiz programları uygular (2).

Arteriyel elastikiyet ile egzersiz arasındaki ilişkiyi araştıran çalışmalar, düzenli egzersizin azalmış arteriyel sertlik ile ilișkili olduğunu göstermiștir. (3). Büyük arterler, sağlıklı bireylerde akış ve basınçtaki dalgalanmaların amplitüdünün düşmesini ve uyumu sağlar. Bununla birlikte arterler elastisitelerini kaybederse, hedef organlara hemodinamik pulsatilitenin aşırı geçişini hafifletme yetenekleri azalır (4).

Arteriyel duvarların sertleșmesi sistolik basınçta artış ve diastolik basınçta düşüş ile birlikte yüksek nabız basıncı ortaya çıkartır. Nabız basıncı ve arteriyel sertlik kardiyovasküler risk faktörlerinin bağımsız göstergelerindendir $(5,6)$.

Büyük damarların viskoelastisitik özelliklerini değerlendirmek amacıyla çeşitli yöntemler geliştirilmiştir. Anjiyografı gibi invazif yöntemler, arter lümeni ve duvar yapısı hakkında değerli bilgiler vermekle birlikte, oldukça karmaşık ve pahalı olmaları nedeniyle klinik kullanımları sinırlıdır. Non-invazif yöntemlerden Dubleks Echo Doppler, Echo-Tracking gibi ultrasonografi temelli yöntemler, bazı arterlerin yapı ve fonksiyonları hakkında bilgi verebilirler. Aort ve ana dallarının viskoelastisitesini değerlendirmede kolay uygulanan non-invazif ve santral bir yöntem olarak NDH ölçümü, arteriyel sertliğin değerlendirilmesinde altın standart kabul edilmektedir (7-9).

Güreş rekabete dayalı bir müsabaka sporu olması nedeniyle, direnç (kuvvet), aerobik (dayanıklılık) ve anaerobik egzersizler yoğun olarak uygulanmaktadır. Ülkemizdeki adolesan elit güreşçilerde arteriyel sertliğin bu egzersizlere tepkisini yeterince araştıran analiz ve çalışmaya rastlanmadı. Bu çalışmamızda uzun süreli ve ağır egzersizin etkilerini göstermek için düzenli antrenman yapan adolesan elit güreşçilerde arteriyel sertlik parametresinin (NDH), aynı yaş aralığındaki sedanter kontrol grubuyla karşılaştırılması amaçlandı.

\section{GEREÇ ve YÖNTEMLER}

Çalışmaya son dört yıldır düzenli güreș antrenmanı yapan 23 adolesan erkek elit atlet ile, yaşları aynı olan ve aktif spor yapmayan 23 sedanter erkek kontrol grubu dahil edildi. Hipertansiyonu (TA>130/80), kalp-damar hastalığl, obezitesi (vücut kütle indeksi $>30 \mathrm{~kg} / \mathrm{m}^{2}$ ), kronik sistemik hastalığı olanlar, güreş dişında aktif sporculuk geçmişi olanlar, sigara kullananlar çalışma dışı bırakıldı. Çalışma öncesi etik kurul onayı ve olgulardan onam alındı. 
Olguların yaş, boy ve vücut ağırlığı ölçümleri yapıldı. Sırtüstü yatış (supin) pozisyonunda, civalı sfigmomanometre ile brakiyal arterden sistolik ve diyastolik kan basınçları ölçüldü. Radial arter üzerinden istirahat nabız değerleri kaydedildi.

$\mathrm{NDH}$, belli mesafeye kadar ayrılmış iki arterin (karotis-femoral, brakiyal-radyal arterler gibi) trasesi üzerine transkutanöz olarak fikse edilmiş iki ultrason ya da basinca duyarlı transdüser kullanarak ölçülebilen bir parametredir (7). NDH ölçümleri bu çalışmada fotopletismografi (PPG) cihazı kullanılarak, supin pozisyonda yapıldı. PPG; nabıza bağlı olan cilt kan akımındaki hacim değişikliklerini ölçmeye yarayan optik bir araçtır. PPG cihazl, kan oksijen satürasyonu ölçümlerinde, kalp monitorizasyonunda ve periferik vasküler ağacı değerlendirmede, nabız geçiş zamanı (NGZ) ve NDH ölçmek için yaygın bir şekilde kullanılmaktadır (10).

NDH hesaplamasında önce suprasternal çentikten orta parmak ucuna kadar uzunluk ölçüldü. Parmak ucuna takılan PPG cihazı ile elde edilen nabız dalgası ve eş zamanlı elde edilen elektrokardiyografi (EKG) kayıtlarından NDH hesaplandı. Yöntemde, EKG'deki R dalgası zirvesi ile nabız dalgasının çıkan kolunun ayak noktası arasındaki süre hesaplanarak NGZ elde edildi (Şekil 1). Ölçülen kol uzunluğunun NGZ'ye bölünmesiyle NDH elde edildi. Ölçüm, ortamın sıcaklığı klima ile $22-24^{\circ} \mathrm{C}$ arasinda otomatik olarak kontrol edilen sessiz bir odada sabah saat 10-12 arasında yapıldı. Katılımcılardan kayıtlamadan en az bir saat önce çay, kahve ve enerji içecekleri içmemeleri istendi. Kayıtlama sırasında hareketsiz kalmaları sağlandı.

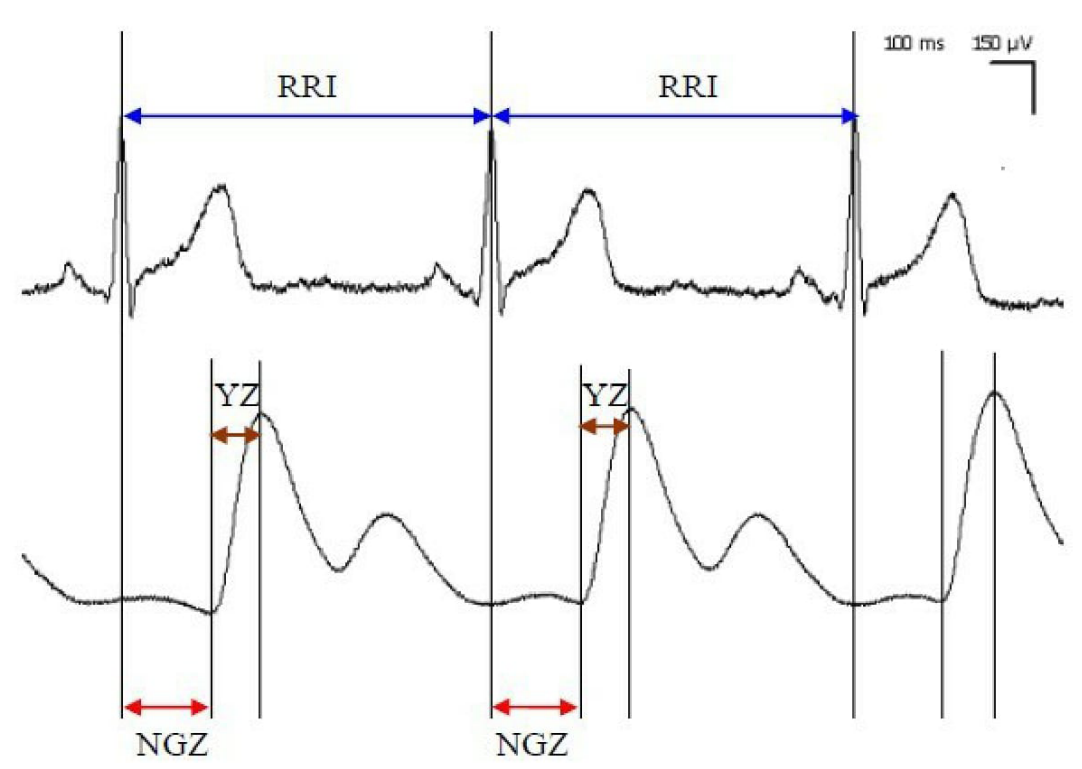

NGZ: Nabız geçiş zamanı

YZ: Yükselme zamanı

Şekil 1. Pletismografik yöntem ile nabız dalga hızı ölçümü. RRI: $R$ - $R$ intervali

Verilerin analizinde SPSS 22.0 (IBM SPSS for Windows version 22, IBM Corparation, Armonk, New York, United States) programı kullanıldı. Kantitatif veriler ortalama \pm standart sapma değerleri şeklinde ifade edildi. Verilerin normal dağılıma uygunluğu Kolmogorov-Smirnov testi ile incelendi. Bağımsız grupların değerlendirilmesi Student t-testi ile yapıldı. Veriler $\% 95$ güven düzeyinde incelendi; $p<0.05$ değeri anlamlı kabul edildi. 


\section{BULGULAR}

Haftada dört gün antrenman (iki gün kuvvet ve dayanıklılık, iki gün kombine egzersiz programı) uygulayan güreşçilerin ortalama spor yaşları $4.3 \pm 0.3$ yll olarak saptandı. Atlet grubu ile kontrol grubu arasında yaş açısından anlamlı farklılık yoktu (p>0.05) (Tablo 1). Kontrol grubunun ortalama boyu atlet grubununkinden anlamlı olarak uzundu ( $\mathrm{p}<0.001)$. Vücut ağırlığ açısından kontrol grubuyla atlet grubu arasında anlamlı farklılık yoktu ( $\mathrm{p}>0.05)$. Kol uzunlukları da farklı değildi (sırasıyla $85.6 \pm 1.8$ ve $84.5 \pm 5.3 \mathrm{~cm}$, $\mathrm{p}>0.05$ ). Kontrol grubunun vücut kütle indeksi (VKI) değerleri atlet grubunkinden anlamlı olarak düşüktü $(\mathrm{p}<0.001)$. Atlet grubunun istirahat nabız ölçüm değerleri ve arteriyel kan basıncı değerleri, kontrol grubundaki değerlerden anlamlı olarak düşüktü (her ikisinde de $\mathrm{p}<0.001$ ). Kontrol grubunun NDH değerleri $(4.66 \pm 0.16 \mathrm{~m} / \mathrm{s})$ atlet grubundakilerden $(4.41 \pm 0.18 \mathrm{~m} / \mathrm{s})$ anlaml düzeyde yüksekti $(\mathrm{p}<0.001)$ (Tablo 1 ve Şekil 2).

Tablo 1. Güreşçiler ve sedanter kontrol grubun demografik dağılımı, NDH değerleri

\begin{tabular}{lccc}
\hline & Güreşçiler $(\mathrm{n}=23)$ & Sedanter grup $(\mathrm{n}=23)$ & p \\
Yaş $(\mathrm{yıl})$ & $16.0 \pm 1.1$ & $15.9 \pm 0.9$ & $>0.05$ \\
Boy $(\mathrm{cm})$ & $164.0 \pm 9.4$ & $171.8 \pm 3.5$ & $<0.001$ \\
Vücut ağırlığı $(\mathrm{kg})$ & $64.5 \pm 17.4$ & $57.8 \pm 8.1$ & $>0.05$ \\
Nabız (istirahat) (atım/dk) & $67.0 \pm 8.0$ & $78.0 \pm 7.0$ & $<0.001$ \\
Kan basıncı (istirahat) (mm Hg) & $100 \pm 6 / 70 \pm 5$ & $111 \pm 8 / 81 \pm 3$ & $<0.001$ \\
VKİ $\left(\mathrm{kg} / \mathrm{m}^{2}\right)$ & $23.6 \pm 3.8$ & $19.5 \pm 2.4$ & $<0.001$ \\
NDH $(\mathrm{m} / \mathrm{sn})$ & $4.41 \pm 0.18$ & $4.66 \pm 0.16$ & $<0.001$ \\
\hline
\end{tabular}

VKİ: vücut kütle indeksi, NDH: nabız dalga hızı

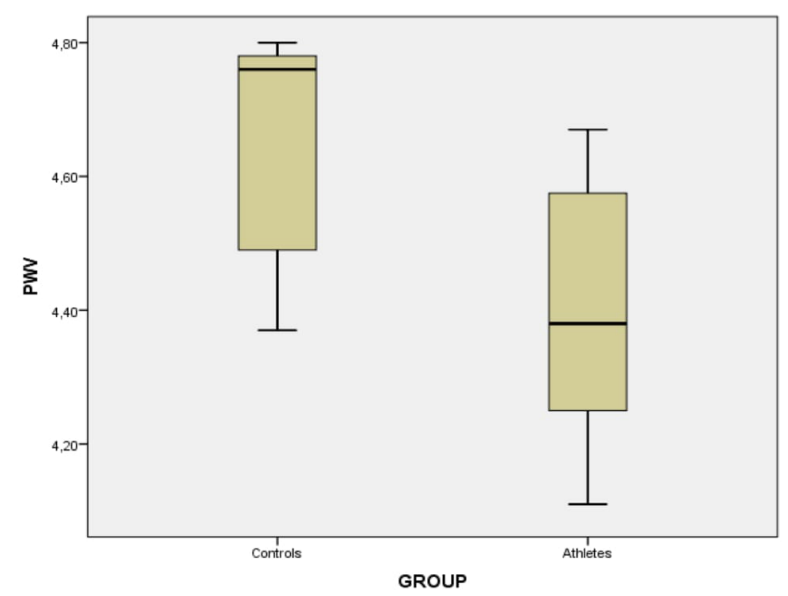

Şekil 2. Her iki grubun nabız dalga hızı değerleri. PWV (NDH): nabız dalga hızı 


\section{TARTIŞMA}

Atlet grubunun kontrol grubuna göre VKİleri yüksek, boyları kısa olarak bulundu. Her iki grup arasında vücut ağırlığı ve kol uzunluğu değerleri arasında anlamlı bir farklılık olmamasına ve güreşçilerin boylarının daha kısa olmasına karşın; atlet grubunda VKİ değerlerinin yüksek bulunması, yapılan kuvvet, dayanıklılık, anaerobik ve kombine egzersizlerin bir sonucu olarak, güreşçilerde kas kütlesinin yoğun olmasına bağlanabilir. Sonuç olarak kas yoğunluğu arteriyel sertlik değerlendirmesi yönünden olumlu bir parametre olabilir.

Güreş sporunda başarı için kas kuvveti, hızlı reaksiyon zamanı, yüksek aerobik ve anaerobik kapasite oldukça önemlidir. Fizik yapı olarak geniş omuzların, uzun kolların ve sağlam bir kas-iskelet yapısının bulunması, bu sporla üst düzeyde uğraşanların kısa sürede fiziksel uyumluluk kazanmalarına olanak sağlamaktadır. Literatürdeki çalışmalarla kıyaslandı̆̆ında, elit adolesan güreşçilerin de aynı özelliklere sahip oldukları görülmektedir $(11,12)$.

Kalp hızı değeri, otonomik sinir sisteminin sempatik ve vagal bileşenleri tarafından kardiyak modülasyonu yansıtan önemli bir belirteçtir. Atletlerin antrenmana uyumlarını ve gelișim zamanlarını izlemek ve daha iyi performanslara yol açacak optimum antrenman yüklerini belirlemek için en kullanışlı araçlardan biridir.

İnsanlarda fiziksel uygunluğun damarsal yapılara olumlu etkileri vardır. Akut egzersiz arter fonksiyonunda çok hızlı değişimlere neden olurken; tekrarlayıcı egzersiz epizodları kronik fonksiyonel adaptasyona ve yapısal arteriyel remodelinge neden olmaktadır. $\mathrm{Bu}$ değişimler yükün karakteristiğiyle doğrudan ilişkilidir (13).

Çalışmamıza katılan elit atletlerin nabız (67.0 0 8.0 atım/dk) ve arteriyel kan basıncı değerleri $(100 \pm 6 / 70 \pm 5 \mathrm{mmHg})$, sedanter kontrol grubu değerlerinden (sırasıyla $78.0 \pm 7.0 \mathrm{atım} / \mathrm{dk}$ ve $111 \pm 8 / 81 \pm 3 \mathrm{mmHg}$ ) anlamlı olarak düşüktü (her ikisi için $\mathrm{p}<0.001$ ). Bu sonuç düzenli aerobik ve anaerobik egzersiz yapan atletlerin kardiyo-vasküler distantibilitesi ile doğru orantılı olarak literatür ile uyumlu bir anlam taşımaktadır (14-16).

Kanın sol ventrikülden çıkan aorta atılması, aortu dilate eder ve arteriyel ağaca belli hızlarda yayılım gösteren bir nabız dalgası oluşturur. $\mathrm{Bu}$ dalganın yayılım hızı arteriyel sertliğin bir ölçütü olan NDH'dır. Hız ne kadar yüksekse arteriyel sertlik o kadar fazla ve arteriyel genişleyebilme kabiliyeti (distansibilite) o kadar zayıftır. Ateroskleroz varlığı ve yaygınlığının noninvazif olarak belirlenmesine yönelik birçok yöntem geliştirilmiştir ve arteriyel sertlik ölçümleri bu yöntemlerin en yaygın kullanılanlarındandır $(17,18)$.

Direnç egzersizlerinin kas-iskelet sistemi üzerinde derin etkileri vardır; fonksiyonel kapasitenin korunmasına ve osteoporozun önlenmesine katkıda bulunur (19). Bununla birlikte, direnç egzersizlerinin kardiyovasküler sistem ve arteriyel uyum üzerindeki etkileri tartışmalıdır.

Kaşıkçığlu ve ark. (20), elit adolesan erkek güreşçilerle sağlıklı kontrol grubu üzerinde, direnç egzersizlerinin kardiyovasküler etkilerini ekokardiyografik oarak değerlendirdikleri incelemede, aort sertliği indeksinin elit atletlerde kontrol grubuna göre anlamlı derecede yüksek ve arteriyel genişleyebilme kabiliyetinin düşük olduğunu saptamışlardır.

Yarışmalı sporla uğraşan kadın atletlerin, sporu bıraktıktan sonraki dönemde, egzersizin, modalitelerine bağlı olarak arteriyel sertlik üzerinde çeșitli etkileri olduğunun gösterildiği prospektif bir çalışmada, aerobik egzersizin normotansif ve hipertansif olgularda arteriyel sertlik üzerinde yararlı bir etkiye sahip olma eğiliminde olduğu saptanmıştır. Direnç egzersizinin tipine ve yoğunluğuna bağlı olarak arteriyel sertlik üzerinde farklı etkilere sahip olduğu görülmüştür. Güçlü direnç egzersizleri, arteriyel sertlikteki artışla ilişkili bulunmuş, yavaş eksantrik tarzda, düşük yoğunluklu direnç antrenmanının, sağlıklı bireylerde alt ekstremitede arteriyel sertlik üzerinde olumsuz bir etkisi görülmemiş; kombine egzersizlerin ise, arteriyel sertlik üzerinde nötr, hatta yararlı bir etkiye sahip olduğu saptanmıştır (21). 
Baykara ve ark. (22), kısa süreli düzenli egzersizin arteriyel sertlik parametrelerini iyi yönde etkilediğini göstermişlerdir. Sedanter bireylerde kısa süreli aerobik egzersizin diastolik duvar stresi, elastik modül üzerine güçlü uzun süreli etkileri olmakla birlikte, arteriyel sertlik ve distansibiliteye etkisiz olduğu gözlenmiştir. Farklı parametrelerin arteriyel sertliği değerlendirmede kullanılması bu sonucu doğurmuş olabilir.

Genç yüzücülerle elit bisiklet sporcularının ve sedanter grubun karşılaştırıldığı bir çalışmada, arteriyel sertliğin (NDH), sedanter yaşıtlarına göre yüzücülerde ve bisiklet sporcularında daha düşük olduğu gözlemlenmiştir (23).

Bizim çalışmamızda adolesan elit atlet grubunun santral arteriyel sertlik ölçüm değerleri (NDH) $(4.41 \pm 0.18 \mathrm{~m} / \mathrm{s})$, sedanter kontrol grubundan $(4.66 \pm 0.16 \mathrm{~m} / \mathrm{s})$ anlamlı düzeyde düşük bulundu $(\mathrm{p}<0.001)$.

Saka ve ark. (24), 17-32 yaş aerobik egzersiz yapan elit atletlerdeki arteriyel sertliğin, aynı yaş grubu anaerobik veya dirençli egzersiz yapan elit atletlere göre farklı olup olmadığını değerlendirdikleri araştırmada, elit basketbolcular ile elit haltercilerin ve sedanter kontrol grubunun NDH ölçümleriyle birliktr ekokardiyografik görüntülemelerini karşılaştırmışlardır. Ekokardiyografik ölçümlerden elde edilen aortik elastik özellikler gruplar arasında farklılık göstermezken, NDH ölçümleri, hem basketbolcular hem de haltercilerde kontrollere göre anlamlı olarak daha düşük bulunmuş, basketbolcular ve halterciler arasında anlamlı fark görülmemiştir. Var olan bilginin aksine, halterciler gibi daha dirençli egzersiz yapan atletlerin arteriyel sertliği önemli ölçüde iyileşmiştir.

$\mathrm{Bu}$ çalışmalardan ve bizim çalışmamızdan çıkan sonuç, uzun vadede arteriyel sertliğin, ağırlıklı olarak direnç egzersizlerinden oluşan spor aktivitelerinden olumlu etkilendiği yönündedir. Her ne kadar akut dirençli ve/veya anaerobik egzersiz sonrasında NDH artışını (arteriyel elastisitenin azaldığını) gösteren sınırlı sayıda çalışma olsa da; halter, güreş gibi sporlarda, hem akut hem de uzun süreli yoğun direnç egzersizlerine kardiyovasküler yanıtın ayrıntılı olarak değerlendirilmesinde yarar vardır. Özellikle uzun süreçte nabız, arteriyel elastisite (NDH), arteriyel kan basıncı gibi parametrelerde olumlu iyileșmeler görülmesi kuvvetle olasıdır.

\section{SONUÇ ve ÖNERILER}

Farklı spor branşlarında antrenmanlar da doğal olarak farklılıklar gösterecektir. Bu nedenle her branşta en üst performansa ulaşmak için antrenman özelliklerinin farklı düzeyde geliştirilmesi, aynı zamanda antrenmanların organizmada olușturduğu etkilerin de iyi bilinmesi gerekmektedir. Arteriyel sertlik sporcular için kardiyovasküler hastalık ve mortalitenin bağımsız bir değerlendirme ölçütüdür. Kuvvet, esneklik, dayanıklılık, sürat ve çabukluk gerektiren performansa dayalı güreş gibi ağır spor dallarında, sporcuların NDH değerleri ve diğer kardiyovasküler parametrelerinin yakından izlenmesi yararlı olacaktır. Egzersizin adolesan güreşçilerde arteriyel sertlik üzerine etkilerini değerlendirmeyi amaçlayan bu çalışmanın, arteriyel fonksiyonun yoğun egzersiz uygulamalarına nasıl yanıt verdiğinin saptanmasına yardımcı olacağı düşüncesindeyiz.

Çalışmaya sınırlı sayıda adolesan elit atlet ve aynı yaş sedanter olguların katılması, sonuçlarımızın belli sınırlarda olmasına yol açmış olabilir. Ayrıca olgularda kuvvet ve dayanıklılığı değerlendiren testlerin yapılmamış olması, santral NDH ile birlikte periferik NDH ölçümün ve diğer kardiyovasküler değerlendirme ölçümlerinin yapılamaması verilerimizi ve çalışmamızı sınırlı kılmaktadır. Her ne kadar $\mathrm{NDH}$, arteriyel sertliği değerlendirmede altın standart kabul edilse de, sadece NDH hesaplayarak arteriyel sertlik hakkında kesin yargıda bulunmak yanıltıcı olacaktır. Bu anlamda geniş sayıda ve farklı sportif aktiviteleri (dirençli, aerobik, anaerobik egzersiz) yapan adolesan elit sporcu grupları üzerinde karşılaştırmalı NDH ve diğer kardiyovasküler parametreleri değerlendiren çalışmalar yapmanın, literatüre ve spor hekimliğine daha fazla katkı sağlayacağı kananatindeyiz. 


\section{KAYNAKLAR}

1. Johnson GO, Cisar CJ. Basic conditioning principles for high school wrestlers. Physician Sportsmed. 1987; 15(1):153-9.

2. Chaabene H, Negra Y, Bouguezzi R, et al. Physical and physiological attributes of wrestlers: an update. J Strength Cond Res. 2017;31(5):1411-42.

3. Schmidt-Trucksass A, Schmid A, Brunner C, et al. Arterial properties of the carotid and femoral artery in endurance-trained and paraplegic subjects. J Appl Physiol (1985). 2000;89(5):1956-63.

4. Mitchell GF, van Buchem MA, Sigurdsson S, et al. Arterial stiffness, pressure and flow pulsatility and brain structure and function: the Age, Gene/Environment Susceptibility-Reykjavik study. Brain. 2011;134( 11):3398-407.

5. Safar ME. Systolic blood pressure, pulse pressure and arterial stiffness as cardiovascular risk factors. Curr Opin Nephrol Hypertens. 2001;10(2):257-61.

6. Karakus M, Akkurt S, Exercise and arterial stiffness. Turk J Sports Med. 2017;52(1):25-35

7. Asinar R: Pulse wave velocity, principles and measurement. In: Asmar R, editor. Arterial Stiffness and Pulse Wave Velocity. Clinical Applications. France: Elsevier, Editions Scientifiques Et, 1999; p 25-55.

8. Luzardo L, Lujambio I, Sottolano M et al. 24-h ambulatory recording of aortic pulse wave velocity and central systolic augmentation: a feasibility study. Hypertens Res. 2012;35(10):980-7.

9. Boutouyrie P, Vermersch S, Laurent S, et al. Cardiovascular risk assessment through target organ damage: role of carotid to femoral pulse wave velocity. Clin Exp Pharmacol Physiol. 2008;35(4):530-3.

10. Zhang XY, Zhang YT. The effect of local cold exposure on pulse transit time. Engineering in Medicine and Biology 27th Annual Conference. Shangai, China, September 14, 2005. Proc IEEE Eng Med Biol Soc. 2005;4: 3522-5.

11. Freischlag, J. Weight loss, body composition and health of high school wrestlers, Physician Sports Med. 1984;12(1):121-6.

12. Aydos L, Taș M, Akyüz M, et al. Genç elit güreșçilerde kuvvetle bazı antropometrik parametrelerin ilişkisinin incelenmesi. AtaBESBD 2009;11(4):1-10.

13. Dong JG. The role of heart rate variability in sports physiology. Exp Ther Med. 2016;11(5):1531-6.
14. Green DJ, Smith KJ. Effects of exercise on vascular function, structure and health in humans. Cold Spring Harb Perspect Med. 2018;8(4):ii.

15. Whelton SP, Chin A, Xin X, et al. Effect of aerobic exercise on blood pressure: a meta-analysis of randomized, controlled trials. Ann Intern Med. 2002;136(7):493-503.

16. Cornelissen VA, Fagard RH. Effects of endurance training on blood pressure, blood pressure-regulating mechanisms, and cardiovascular risk factors. Hypertension. 2005;46(4): 667-75.

17. Arnett DK, Evans GW, Riley WA. Arterial stiffness: a new cardiovascular risk factor? Am J Epidemiol. 1994; 140(8):669-682.

18. Yildiz M, Aykan AC, Hasdemir H. Assessment of arterial stiffness with pulsewave velocity or augmentation index: which method is the best? Scientific letter. Türkiye Klinikleri J Med Sci. 2012;32(1):214-7.

19. Pollock ML, Franklin BA, Balady GJ, et al. AHA Science Advisory. Resistance exercise in individuals with and without cardiovascular disease: benefits, rationale, safety, and prescription: An advisory from the Committee on Exercise, Rehabilitation, and Prevention, Council on Clinical Cardiology, American Heart Association; Position paper endorsed by the American College of Sports Medicine. Circulation 2000;101(7):828-33.

20. Kasikcioglu E, Oflaz $\mathrm{H}$, Akhan $\mathrm{H}$, et al. Left ventricular remodeling and aortic distensibility in elite power athletes. Heart Vessels. 2004;19(4):183-8.

21. Koshiba H, Maeshima E, Okumura Y. The relationship between arterial stiffness and the lifestyle habits of female athletes after retiring from competitive sports: a prospective study. Clin Physiol Funct Imaging. 2017; 37(5):474-80.

22. Baykara M, Demirel A, Yavuzatmaca I, et al. Response of arterial stiffness four weeks after terminating shortterm aerobic exercise training in a sedentary lifestyle. J Ultrasound Med. 2017;36(2):353-9.

23. Nishiwaki M, Takahara K, Matsumoto N. Arterial stiffness in young adult swimmers. Eur J Appl Physiol. 2017; 117(1):131-8.

24. Saka T, Sekir U, Dogan A, et al. Arterial stiffness differences between aerobically and resistance trained Turkish elite athletes. The Anthropologist. 2016;24(2): 429-39. 